\title{
A free dialogical logic for surrogate reasoning: generation of hypothesis without ontological commitments
}

\author{
(Una lógica dialógica libre para el razonamiento subrogativo: \\ generación de hipótesis sin compromisos ontológicos)
}

\author{
Juan REDMOND* \\ Universidad de Valparaíso (Chile)
}

\begin{abstract}
This article aims to present a Free Dialogic Logic [FDL] as a general framework for hypothesis generation in the practice of modelling in science. Our proposal is based on the idea that the inferential function that models fulfil during the modelling process (surrogate reasoning) should be carried out without ontological commitments. The starting point to achieve our objective is that the scientific consideration of models without a target is a symptom that, on the one hand, the Applicability of Logic should be considered among the conditions of adequacy that should take into account all modeling process and, on the other, that the inferential apparatus at the base of the surrogate reasoning process must be rid of realistic assumptions that lead to erroneous conclusions. In this sense, we propose as an alternative an ontologically neutral inferential system in the perspective of dialogical pragmatism.
\end{abstract}

KEYWORDS: targetless models; dialogic; surrogate reasoning; free logic.

RESUMEN: El presente artículo tiene como objetivo presentar una Lógica Dialógica Libre [FDL] como marco general para la generación de hipótesis en la práctica de la modelización en ciencia. Nuestra propuesta parte de la idea de que la función inferencial que cumplen los modelos durante el proceso de modelización (razonamiento subrogativo) debe realizarse sin compromisos ontológicos. El punto de partida para lograr nuestro objetivo es que la consideración de modelos sin objetivo (targetless models) es sintoma de que, por un lado, la Aplicabilidad de la Lógica debe ser considerada entre las condiciones de adecuación que debe tener en cuenta todo proceso de modelación y, por otro lado, que el aparato inferencial en la base del proceso de razonamiento subrogativo debe deshacerse de suposiciones realistas que conducen a conclusiones erróneas. En este sentido, proponemos como alternativa un sistema inferencial ontológicamente neutro en la perspectiva del pragmatismo dialógico.

PALABRAS CLAVE: modelos sin diana; dialógica; razonamiento subrogativo; lógica libre.

\footnotetext{
* Correspondence to: Juan Redmond. Instituto de Filosofía, Facultad de Humanidades y Educación, Universidad de Valparaíso. Serrano 546, Barrio Puerto, Valparaíso (Chile) - juan.redmond@uv.cl - https://orcid.org/0000-0003-3436-9490

How to cite: Redmond, Juan (2021). "A free dialogical logic for surrogate reasoning: generation of hypothesis without ontological commitments"; Theoria. An International Journal for Theory, History and Foundations of Science, 36(3), 297-320. (https://doi.org/10.1387/ theoria.21902)
}

Received: 2020-07-09; Final version: 2021-04-19.

ISSN 0495-4548 - eISSN 2171-679X / (c) 2021 UPV/EHU 


\section{Introduction}

The objective of the present article is to propose a Free Dialogical Logic (FDL henceforth) that addresses the logical problems that arise when the generation of scientific hypotheses correspond to portions of the world whose existence is uncertain or debatable. In particular, we will focus on cases when we must infer scientific hypotheses from models that point to that kind of portions of the world. ${ }^{1}$ Thus, if a model should allow us to generate hypotheses about ontologically uncertain phenomena, which is identified as the target in the generalized literature, our point is that the applicability of logic must be considered between the conditions of adequacy and that the generation of hypothesis should be done only from a logical framework that takes into account this feature. The latter considerably restricts our interest to those modeling cases, where the ontologically uncertain phenomena, due to their unclear status, justify the denomination of targetless cases. Therefore, the question that guides our work is which is the most adequate inferential frame for the generation of hypotheses from models about ontologically controversial portions of the world. And according to this, we aim to propose and justify, within the framework of dialogical pragmatism, a proof system without ontological commitments, suitable for targetless cases.

\section{Targetless and Ontology}

The notion of targetless models is recognized in the general literature (cf. Frigg and Nguyen, 2017) as one of the conditions of adequacy that any modeling approach must satisfy in order to be suitable. The notion points to the fact that the modeling process is carried out without a target or portion of the world (phenomena) to which the model points. Indeed, we believe that this explanation of a modeling process with an absent target is not very precise. Moreover, at first sight, it seems nonsensical, given the subrogating condition that models possess: a model is always the model of something ${ }^{2}$. However, we can try to understand this absence in the following way: targetless could happen either because models do not require a target, or because the model assumes that there should be a portion of the world but it is not or does not exist. The first vision, for example, corresponds to the socalled 'toy models' according to Luczak (2017). In this article, we will focus on the inferential issues of the latter two. That is, from a logical point of view, how is it possible to have a model without a target, if reasoning generated from models must yield claims about the target of the models (the phenomena).

So, what does it mean then at first sight that we have a modeling process, but there is no target to which the model is addressed? Where does the information about the absence

1 Our proposed use of FDL is not exclusive to the modeling process. Extending the requirement of a neutral logic to the other scientific domains of hypothesis generation (abduction, etc.) is a task for a future article.

2 For example, in a perspective that defends an epistemic point of view for the representational function of models and denies a demarcation criterion, all objects attain this new double condition at the moment they are invested with the condition of being modeling something. This double condition, that of being itself and at the same time being something else is achieved according to each approach to the notion of representation (similarity, morphism, being in the place of, inferential point of view, etc.). 
of a target come from? At first, the targetless's condition of a model seems to be the result of the confrontation of a datum (the absence of $\mathrm{T}$ ) with a complete process, but not necessarily null. Indeed, it is considered that targetless is not a clause to invalidate modeling processes. In this regard, we believe that there are in general two options: either we deny that the target could not exist (we deny targetless), or we try to explain what happens. We distance ourselves from the first position because we consider it to be anti-intuitive. We believe that there are numerous cases of successful models, even though we know that the target they are aiming at, does not exist or it is not as described by the model (for example, when we appeal to the planetary model of the atom to explain Coulomb's law, even though we know that this is not the reference of the word 'atom'). Thus stated, targetless is not considered a hypothesis, a condition, or a presupposition, but a fact that results from experimental corroboration (sometimes a fortiori). We mean, "the targetless condition" of the model is not part of any process of modeling. And from a logical point of view, which is the purpose of the present article, there seems to be no special consideration of any kind regarding the generation of hypotheses, whether it is done from an unrealistic model (models of ether, phlogiston, etc.), or a shark model for hydrodynamic studies (model of a real shark for submarine engineering). Especially regarding the ontological status of what those models point to. For this reason, we believe that it is worth introducing a distinction between this approach of targetless, which we will call static, and the point of view that aims to integrate the absence of the target in the process of generating hypotheses and that we will call dynamic. We will develop the latter in point 5.

In general, the absence of a target triggers at least two kinds of problems: one is epistemological and concerns scientific realism. The second is logical and points to the inferential function of the model, i.e., the generation of hypotheses about a portion of the world (the target of the model).

\section{Modeling and realism: where is the target?}

The scientific realism to which we refer, as Chakravarty (2017) points out, is a positive epistemic attitude toward the content of our best theories and models. Indeed, this epistemic attitude results in beliefs in different aspects of the world described by the sciences. We also consider relevant to our work realistic approaches that focus on the following aspect: the successful reference of theoretical terms to things in the world, both observable and unobservable. And this presupposes the metaphysical dimension of realism: the mind-independent existence of the world investigated by the sciences. And although this is an uncommon position in contemporary theoretical developments - as Chakravarty points out-, it reveals a maxim that governs - from our point of view - all scientific realism: Science aims to give a literally true account of the world or reality. The latter, in turn, leads us to the epistemological dimension of it, that is, that the totality of knowledge of the world is the set of scientific theoretical claims (interpreted literally as describing an independent world or reality). How could we then have knowledge according to the realistic approaches, if the target system does not exist? The latter is indeed a serious problem. Even more so if we take into account, from the perspective of scientific representation, all the theoretical commitments underlying the different approaches. For example, if we consider the similarity and structuralist conceptions. One reaction to 
these problems is the anti-realist approaches that distance themselves from the notion of representation.

However, the aim of our article is not to contribute to this debate. In effect, although the notion of targetless challenges the realist commitments of theories, our aim here is not to postulate an anti-realistic or antirepresentationalistic approach to modeling, but to analyse the realist presuppositions present in the inferential function that models perform (surrogate reasoning) and their consequences.

\section{Targetless and applicability of logic: surrogate reasoning}

Surrogate reasoning is the name given to the process of generating hypothesis in the practice of modeling. The term was introduced by Swoyer (1991, p. 449) and, as Frigg and Nguyen point out, is about reasoning conducted on models that yield claims about their targets (2017, p. 51). We assume from this definition that it is a logical process. The hypothesis generated still remains - as in the most epistemological approaches - a tentative assumption or concession made for the sake of argument in order to draw out and test its logical or empirical consequences. Our aim here is to point out that the ontological presuppositions of scientific realism present in the underlying logic of surrogate reasoning lead to erroneous conclusions - of which targetless is a symptom - and should therefore be abandoned. ${ }^{3}$ For symptoms, we mean an anomaly that requires a new perspective.

It is important to note that, from our point of view, as we pointed out above, we are not considering models as prescribing what reality is like. Instead, it is about modeling to understand what reality is like or how it works. In these cases, surrogate reasoning consists of generating hypotheses from the model and then testing them experimentally (directly and indirectly), in the portion of the world where the model is focused. The success of the latter depends, among other things, on the degree of accuracy with which the model relates to the portion of reality at which it is aimed (and according to the chosen theoretical perspective). Indeed, it can be seen that the modeling process as a whole (including recognition of a problematic portion of reality, elaboration of a model, measurement, testing, data collection, etc.), goes beyond the surrogate reasoning function of the model. But reasoning conducted on models is a crucial factor in determining whether the model is adequate or not.

Thus, surrogate reasoning, as a condition for models, does not mean that we are dealing with a new kind of generation of hypothesis. What is new, according to our point of view, is that we are addressing a dynamic and interactive frame where the model and the targeted portion of reality exchange information ${ }^{4}$.

Now, we will focus on highlighting the problems of choosing an ontologically non-neutral logic as the basis for surrogate reasoning. Talking about truth, falsity, and por-

3 We repeat that this does not mean that we propose to abandon the scientific realism of theories. We can use a neutral logical apparatus for the generation of hypotheses, independently of the theoretical assumptions that underlie the epistemological approach within which the modeling practice is carried out.

4 In another article we have argued that this interactive relationship, to be captured correctly, requires an appropriate dynamic and interactive theoretical approach (cf. Redmond, 2021). 
tions of reality bring us to - from a logical point of view - the most consolidated logical frame in science: classical logic. Our objective is to expose the ontological commitments at the base of this frame and to align ourselves with the critique mainly made by Lambert (2003) and Bencivenga (1986) and their proposal of a free logic. According to this, now we introduce general insights about the semantic of classical logic and then the critics from the free logic perspectives.

For the semantic of classical logic, following Shapiro and Kouri Kissel (2018), we have:

- A set of non-logical terminology $K$.

- An interpretation for the language $L 1 K=$ is a structure $M=\langle d, I\rangle$

- $d$ is a non-empty set, called the domain-of-discourse

- $I$ is an interpretation function.

And one of the most relevant features of this semantics is that.

If $\mathrm{k}_{1}$ is a constant in $K$, then $I\left(\mathrm{k}_{1}\right)$ is a member of the domain $d$.

Thus, as the authors signalized, every constant denotes something. Systems, where this is not assumed, are called free logics. The two logical principles that reflect this compromise are (i) "the principle of Existential Generalization (EG): $F b \rightarrow \exists x(F x)$, i.e., If $b$ is $F$, then there is something that is $F$. The second principle - as Reicher signalizes (2019) - is "less prominent, rather seldom explicitly stated, but often tacitly assumed." This is about the Predication Principle (PP): $F b \rightarrow \exists x(x=b)$, i.e., If $b$ is $F$, then $b$ exists / there is something identical with $b$.

These two principles, when present in scientific discourse, especially in modeling, lead to consequences that in some cases contradict hard empirical facts and trivial truths about the ontological status of the portions of the world implicated. Let us consider the following case as an example of the difficulties that may result from not properly considering the applicability of the underlying logic. The planetary model created to explain the anomalies in Mercury's orbit (the 43 arcsecond variation that had been detected at the perihelion of the planet Mercury), and which included a planet between itself and the sun: Vulcan (cf. Levenson, 2017). No doubt the model explained well what was observed, just as the planetary model of the atom allows a good understanding of the phenomena through Coulomb's law for electric charges. But in both cases, the success of the models is not a proof of the existence of that to which the model was aiming. But the latter contradicts the semantics of classical logic. In effect, for the Vulcan case, according to the semantics of classical logic, there must be at least one individual $\mathrm{k}_{\mathrm{i}}$ who satisfies the properties assigned to the model: ' $\mathrm{A}=\mathrm{k}_{\mathrm{i}}$ is a planet between the Sun and Mercury and produces disturbances in Mercury's orbit'. But at the same time, from the assertion that such an individual fulfills such a property $\left(\mathrm{Ak}_{1}\right)$, we can infer - according to the principles that govern classical logic - that there must exist at least one individual with this property: $\mathrm{Ak}_{1} \rightarrow \exists \mathrm{xAx}$ (Specification, i.e., the existential quantifier ranging over the domain of existing beings). But if we transfer this outcome to the phenomena (the target of the model), it will lead to a predictable failure. But the interesting thing is that the failure is not due to a problem of the standard of

5 In this sense we reject Levy's idea that a model, sometimes, is proposed in a non-committal spirit (Levy, 2014, p. 797). Especially from an inferential point of view, using classical logic there is no way out of its ontologically committed semantic. 
adequacy and the possibility of misrepresentation. This is a case where we apply the wrong logic. For if, as in the case of anomalies in the orbit of Mercury, we model a portion of reality that that is unknown to us and that we do not have certainty about the existence or not of entities in it, we cannot use a logic with ontological commitments for its singular terms $\left(\mathrm{k}_{\mathrm{i}}\right)$. A Free Logic, from our point of view, is the most prominent frame that acknowledged this problem. In effect, Free Logic aims to invalidate specification and particularization, both. The result is a logic free of ontological commitments. Our contribution (below) follows these insights.

\section{A dynamic point of view of targetless}

Now, taking another step in the direction of our proposal, we would like to offer a dynamic point of view of targetless. In order to achieve our objective, we will take into account the following two elements: the first is to understand targetless as a case of ontological indeterminacy (epistemic gap), that is present in specific cases of the practice of modeling. The second aspect, which relies on the first one, aims at integrating this indeterminacy into the inferential process that accomplishes the model. Both elements can be achieved, from our point of view, only using a free logic for the generation of hypothesis from the model (surrogate reasoning). That is, in other words, a neutral logic is justified especially in cases in which ontologically uncertain phenomena are modeled. Modeling portions of the world that are ontologically uncertain is more common than you might think and is perhaps the most challenging and enriching part of scientific modeling.

In general, we believe that we speak of ontologically uncertain phenomena in the following cases:

i) we know there is something but we don't really know what it's like [If we think, for example, of the different shapes given to the atom from Dalton to Bohr];

ii) we don't know if there is something or not [if we think of the Planetary Model that proposed the planet Vulcan between Mercury and the Sun];

iii) we know that such a thing doesn't exist [models of perfect agents (perfect agents doesn't exist)].

Of course, these are special cases of modeling, but especially in these cases, we believe that the caution or parsimony that should characterize the experimentation with observables and non-observables (and especially cases $i$, ii, and $i i i$ ), should be reflected inferentially in the use of a neutral frame. ${ }^{6}$ The final corroboration or proof of the existence or non-existence of something must be considered out of definitely outside the inferential scheme of proposing hypotheses about the target system. ${ }^{7}$ But the inferential basis of surrogate reasoning cannot be indifferent to the absence of this corroboration or proof.

6 A neutral logic such as the one we propose would provide us with a deflationary and/or minimalist alternative with respect to the truth (cf. Contessa, 2007; Suárez, 2015), offering the ludic semantics (game theory) of Dialogic Logic as an alternative to a referentialist semantics such as that of classical logic.

This does not mean that realism is abandoned, that is, it can continue to be defended despite the neutrality of the ontologically neutral action of proposing hypotheses. Otherwise modeling would logically become a machine to produce existing ones: we make a model on a computer, then verify experimentally one of its hypotheses and its target would instantly appear in reality (Ex Nibilo Fiat). 
It should be noted that, by their subrogating character, the conclusions drawn in a model are also, as hypotheses, claims about the ontologically problematic portion to which the model points. But once the hypothesis has been positively corroborated, it would be a mistake to say that what is true in the model is also true in reality. And this is due, as we pointed out above, to the referentialist semantics that underlies the notion of truth in classical logic. For example, it is quite possible to positively corroborate hypotheses obtained from a model consisting of a frictionless plane. But it seems unacceptable that we should therefore conceive that there exists such an impossible thing as a frictionless plane. The same applies to other types of unrealistic models that Frigg gathers in the following list (2010, p. 257): Frictionless planes, spherical planets, infinitely extended condenser plates, infinitely high potential wells, massless strings, populations living in isolation from their environment, animals reproducing at a constant rate, perfectly rational agents, markets without transaction costs.

From our point of view, then, targetless would mean that the model points to ontologically uncertain phenomena and that this fact must be taken into account in the inferential function of the model (surrogate reasoning), which justifies the use of a neutral logic. In the following, we present the dialogical frame for an ontologically neutral logic.

\section{Modeling from a logical point of view}

In this section, we will develop an ontologically neutral logic for the surrogate function that is inferentially fulfilled by the models. We have chosen the approach of dialogical pragmatism for this purpose. In effect, we think that in general the process of modeling could be better understood as an interactive process. The agents of the interaction, in our proposal, are the model and the target system, and the dynamic approach of dialogics could illuminate aspects that are lost in other static points of view.

We will develop this section in two parts. In the first part (I) we will present the dialogic frame and in the second part (II) we will present a Free Dialogical Logic (FDL).

\section{(I) The Dialogical Frame ${ }^{8}$}

Dialogues are mathematically defined language games that establish the interface between the concrete linguistic activity and the formal notion of demonstration. Two interlocutors (Proponent and Opponent) exchange movements that are concretely linguistic acts. The Proponent enunciates a thesis, the thesis of the dialogue, and undertakes to defend it by responding to all the opponent's criticisms. The allowed criticisms are defined in terms of the structure of the statements affirmed in the dialogue. For example, if a player affirms conjunction $\mathrm{A}$ and $\mathrm{B}$, at the same time he gives the opponent the possibility to choose one of the two and to demand that he affirm it. The very notion of asserting is defined by the context of critical interaction: asserting means committing oneself to provide justification to a critical interlocutor. But in dialogues there is no general theory of justification but only insofar as they are logically complex statements that find their justification from simple state-

\footnotetext{
8 For a more detailed presentation see the Appendix at the end of this article.
} 
ments. In turn, simple statements are justified in reciprocal action with the critical interlocutor. That is, as the rule exhorts, the Proponent may consider an elementary statement justified, if and only if the Opponent has granted that justification. This rule confirms the formality of the dialogues: the Proponent wins without presupposing justifications for any particular statement.

A formal dialog (Keiff, 2011) follows two kinds of rules: rules of particles and structural rules according to the following extension of the first-order language:

FO $[\tau]$, as the result of enriching a first-order language over vocabulary $\tau$ with the following metalogical symbols:

i) two force symbols, ? and !;

ii) the symbols $1,2, \forall x / c, \exists x$ (where $x$ and $c$ stand, respectively, for any variable and any constant of the vocabulary $\tau)$;

iii) two labels, $\mathbf{O}$ and $\mathbf{P}$ (standing for the players, Opponent and Proponent, respectively).

\section{Particle or local rules}

The particle rules constitute the local semantics of a logic, for they determine the dialogical meaning of each logical constant. They abstractly describe the way a formula of a given main connective may be objected to (challenge), and how to answer the objection (defense). Particle rules make no reference to the context of argumentation in which the rule is applied. But they are intrinsically dependent on the notion of dialogue, since they describe sequences of language acts.

An example for the conjunction $(\wedge)$ :

\begin{tabular}{cccc}
\hline & Assert & Challenge & Defense \\
\hline$\wedge$ & $\mathrm{X}-$ !- $\mathrm{A} \wedge \mathrm{B}$ & $\mathrm{Y}-$ ?-1 or $\mathrm{Y}-$ ?-2 & $\mathrm{X}-$ !-A resp. $\mathrm{X}-$ !- $\mathrm{B}$ \\
\hline
\end{tabular}

\section{Structural or global rules}

In the same way as particle rules describe the local meaning of the logical constants, structural rules determine their global semantics leading the general organization of the dialogues. The structural rules are meant to organize the application of the particle rules in such a way that the set of moves resulting from the application of the rules to an initial formula (called the thesis) yields a dialogue that can be seen as a valid argument for the thesis.

A particular development of both of these rules will be given below for a targetless Dialogical Logic.

\section{Crucial to the dialogic approach are the following points}

1. The distinction between local meaning (rules for logical constants) and global meaning (included in structural rules).

2. Rules for anonymous players for local meaning.

3. The distinction between the game level (local winning or game-winning) and the strategic level (existence of a winning strategy). 
4. A notion of validity equivalent to a winning strategy for $\mathrm{P}$.

5. The notion of triumph in a formal game, rather than a winning strategy in a model.

\section{Global Meaning}

As mentioned above, the global sense is defined by structural rules that determine the general development of the games, specifying who starts, what movements are allowed and in what order, when a game ends, and who wins and when (see Appendix I). Structural rules include the following:

Formal Rule: P cannot affirm an elementary proposition unless $\mathrm{O}$ does so first. Elementary propositions cannot be attacked.

This rule is one of the most outstanding features of dialogic logic. As discussed in Marion and Rückert (2015), it goes back to Aristotle's reconstruction of Platonic dialectics: the main idea is that, when an elementary proposition is challenged (attacked), then the only possible answer - from an argumentative point of view - is to appeal to the opponent's concessions. That is, without making use of an authority beyond the movements presented during the argumentative interaction. In fact, one might see the formal rule as the implementation of a type of copying strategy: my reasons for asserting such a proposition are exactly the same as yours when you granted the same proposition (cf. Rahman et al., 2009; Rahman and Keiff, 2010).

Now, if the ultimate foundations of a dialogical thesis are elementary propositions and if this is done through the use of the formal rule, then the dialogues are in this sense necessarily asymmetrical. In fact, if both contenders were restricted by the formal rule no elementary proposition could be asserted. Therefore, we implement the formal rule by designing a player, called the Proponent, whose statements of elementary propositions are restricted by this rule. It is the victory of the proponent that provides the dialogic notion of validity. More precisely, in the dialogical approach, validity is defined through the notion of winning strategy, where winning strategy for $\mathrm{X}$ means that for any choice of movements of $\mathrm{Y}, \mathrm{X}$ has at least one possible movement at its disposal, such that the $(\mathrm{X})$ wins:

Validity (definition): A proposition is valid in a given dialogic system if and only if $\mathrm{P}$ has a formal winning strategy for this proposition.

\section{(II) A free Dialogical logic for SURRogate REASONING}

A Free Dialogical Logic (FDL) is a free and dynamic dialogical logic for abstract objects. FDL follows the general insights of the Free Logic developed by Karel Lambert (2003). The objective is to elaborate a logic that is free from the ontological commitments that generate Specification and Particularization in classical logic (Frege-Russell-Quine). It is dynamic because existence in FDL is an act of choice. In fact, dialogical logic distances itself from the use of predicates of existence (static perspective) and proposes a pragmatic approach to the notion of existence through the notion of use (Particle and Structural Rules). 
Our Free Dialogical Logic has three sources:

i) The notion of introduction coming from Frege's Nightmare (Rahman et al., 1997; Rahman, 2001).

ii) The notion of symbolic status of Hugh MacColl (1906).

iii) The notion of ontological dependency coming from the notion of Artefacts developed by Amie Thomasson (1999).

\section{(i) Frege's Nightmare and introduced constants}

Frege's Nightmare was the name of a dialogical formulation developed by Shahid Rahman (2001) that collects and continues results published in Rahman et al. (1997). This new perspective proposes to place restrictions on the introduction of constants in the context of quantification. Therefore, constants would have a formal use and would allow the development of a paraconsistent and intuitionistic dialogical logic. The device with which this restriction is executed using a special structural rule called the "rule of introduction". This rule stipulated - in the dialogical frame - the interaction between choices and propositions and was the first attempt to invalidate Specification and Particularisation with the unwanted consequence that all formulas starting with an existential quantifier are invalid. For the development of TDL in the present article we will avoid these undesired consequences by incorporating specific devices: the notions of dependency and symbolic constants.

Rule of Introduction: ${ }^{9}$ Let us say that the singular term $\mathrm{k}_{\mathrm{i}}$ played by $\mathrm{X}$ has been introduced if:

1. X brings forward $\varphi\left[\mathrm{x} / \mathrm{k}_{\mathrm{i}}\right]$ to defend an existential expression of the form $\exists \mathrm{x} \varphi$

2. $\mathrm{X}$ attacks $\forall \mathrm{x} \varphi$ with $<$ ? - $\mathrm{x} / \mathrm{k}_{\mathrm{i}}>$, where $\mathrm{k}_{\mathrm{i}}$ does not occur in the play before.

[introduced constants]: This rule, then, allows us to define an introduced constant as that which comes from 1 or 2 .

In general terms, the notion of introduction makes it possible to recognize those constants that are under the scope of classical quantifiers or loaded ontologically.

\section{(ii) Symbolic status of constants}

Symbolic Constants are those in principle that are outside the scope of quantifiers. Since they are beyond the scope of classical quantifiers, we sustain that we do not know if they are ontologically charged or not. It is a moment of epistemic indetermination that the Scottish logician Hugh MacColl (1906) capture in his logical language by the notion of "symbolic constants". MacColl postulates a kind of logic of non-existence that contemplates a symbolic domain of individuals. It introduces two mutually complementary classes: the class of existing beings $\left(e_{1}, e_{2}, \ldots\right)$ and the class of non-existent beings $\left(0_{1}, 0_{2}, \ldots\right)$. But at the same time, it speaks of a third class called "symbolic" and the latter would include the two precedents. A symbolic individual could be existing or non-existent.]

\footnotetext{
9 In previous versions (cf. Rahman et al,, 1997; Rahman, 2001) only O could introduce constants.
} 
[symbolic constants]: a symbolic constant is one that appears in the thesis or played by $\mathrm{P}$, but never introduced.

\section{(iii) Ontological dependency}

To implement the notion of dependence in dialogic we introduce, then, the predicate of dependency relationship $D$ to which we will give a specific semantics: $D \mathrm{k}_{\mathrm{i}} \mathrm{k}_{\mathrm{j}}\left(\mathrm{k}_{\mathrm{i}}\right.$ depends ontologically on $\mathrm{k}_{\mathrm{j}}$ ). This predicate of dependency was inspired by the work of Amie Thomasson (1999) who proposed it to give identity conditions to non-existent beings. The idea is that if a constant $\mathrm{k}_{\mathrm{i}}$ must count as a nonexistent, it must be inscribed in an ontological dependency relation with respect to constant $\mathrm{k}_{\mathrm{i}}$ that corresponds to an existing object (independently). This notion helps us to distinguish between existing objects and non-existent objects. By definition we say, that non-existent objects are dependent while existing ones are independent.

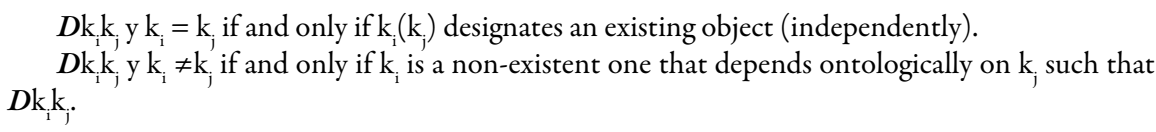

\section{Rules for $F D L$}

The Free Dialogical Logic (FDL) for targetless models we propose is developed in two phases: a symbolic stage and an actualist stage. Both phases are based on the same Particle Rules:

Particle Rules for TDL

\begin{tabular}{|c|c|c|c|}
\hline & Assertion & Challenge & Defense \\
\hline \multirow[t]{2}{*}{$\wedge$} & $X-!-A \wedge B$ & $Y-?-\wedge_{1}$ & $X-!-A$ \\
\hline & & $Y-?-\wedge_{2}$ & $\mathrm{X}-!-\mathrm{B}$ \\
\hline$\vee$ & $X-!-A \vee B$ & $Y-?-V$ & $X-!-A$ or $X-!-B$ \\
\hline$\rightarrow$ & $\mathrm{X}-!-\mathrm{A} \rightarrow \mathrm{B}$ & $Y-!-A$ & $\mathrm{X}-!-\mathrm{B}$ \\
\hline$\neg$ & $\mathrm{X}-!-\neg \mathrm{A}$ & $Y-!-A$ & - \\
\hline$\forall$ & $\mathrm{X}-\forall \mathrm{x} \Phi$ & $\mathrm{Y}-?[\Phi(\mathrm{a} / \mathrm{x})]$ & $\mathrm{X}-\Phi(\mathrm{a} / \mathrm{x})$ \\
\hline$\exists$ & $\mathrm{X}-\exists \mathrm{x} \Phi$ & $Y-?-\exists$ & $\mathrm{X}-\Phi(\mathrm{ai} / \mathrm{x})$ \\
\hline
\end{tabular}

Next, we will only give the rules for a first-order propositional system.

\section{Structural rules for the symbolic stage of FDL}

A play (or dialogue) is a sequence of moves that follows the game rules. The structural rules give the precise conditions under which a given sentence is a play. The dialogical game for $\varphi$, written $\mathrm{D}(\varphi)$, is the set of all plays with $\varphi$ as the thesis (see the Starting rule below). 
The structural rules are the following:

SR-0 (Starting rule): The expressions of a dialogue are numbered, and are alternately stated by $\mathbf{P}$ and $\mathbf{O}$. The thesis is number 0 , and is asserted by $\mathbf{P}$. All moves following the thesis are responses to a move played by another player, and obeying particle rules and other structural rules. $\mathrm{D}_{(\mathrm{A})}$ is called a dialogue that starts with thesis $\mathrm{A}$, even moves are moves made by $\mathbf{P}$, odd moves are made by $\mathbf{O}$.

From here the player chooses to play according to classic rules (SR-1cl) or intuitionist rules $($ SR-1i).

SR-1i (Intuitionistic game-playing rule): With each move, each player can either challenge a complex formula stated by the other player, or defend himself from the last challenge against which he has not yet defended himself. You can wait to defend yourself against a challenge while there are still challenges to play. If it is X's turn to play the move $\mathrm{n}$, and $\mathrm{Y}$ has played two challenges with moves $\mathrm{l}$ and $\mathrm{m}$ (with $\mathrm{l}<\mathrm{m}<\mathrm{n}$ ), to which $\mathrm{X}$ has not yet replied, $\mathrm{X}$ can no longer defend himself against 1 . In short, one can only defend oneself against the last challenge not yet defended.

Example: we have $Y=O$ and $X=P$

\begin{tabular}{|c|c|c|c|c|}
\hline & $\mathrm{O}$ & & $\mathbf{P}$ & \\
\hline$l$ & challenge & No answer & & \\
\hline \multirow[t]{2}{*}{$m$} & challenge & No answer & & $n$ \\
\hline & & $\begin{array}{l}\text { In the move } \\
\text { possible to } \mathrm{r}\end{array}$ & $\begin{array}{l}\text { that follow } m \text { it is not } \\
d \text { to the challenge } 1\end{array}$ & \\
\hline
\end{tabular}

SR-1cl (Classical game-playing rule): At each move, each player can either challenge a complex formula stated by the other player, or defend himself against any challenge by the other player (including those to which he has already responded).

SR-2 (Branching rule): O generates two separate dialogues when it makes the following choices:

1. Defend a disjunction.

2. Challenge a conjunction.

3. Respond to the challenge of a conditional.

Each of these choices gives a new branch, that is, a new part. However, the choices of the Proponent do not generate new branches.

SR-3 (Formal rule): The proponent may not introduce atomic formulas: any atomic formula in a dialogue must first be introduced by the opponent. To challenge atomic formulas is not allowed. 
SR-4 (Ranking rule): Opponent and the Proponent successively choose a positive integer called repetition rank. The role of these integers is to ensure that every play ends after finitely many moves by setting the player's repetition rank as the maximum number of times he can challenge or defend against a given move of the other player.

SR-5 (On symbolic constants): the Proponent defends an existential quantifier or attacks a universal quantifier with symbolic constants or already introduced by the opponent.

Symbolic constants $=$ in the thesis or played by P but never introduced.

SR-6 Winning Rule: A dialog is closed if, and only if, it contains two occurrences of the same atomic formula, labeled X and Y respectively. Otherwise, the dialogue remains open. The player who has stated the thesis wins the dialogue if and only if the dialogue is closed. A dialog is finished if and only if it is closed, or if the rules (structural and particle rules) do not allow any other moves. The player who played the role of opponent won the dialogue if and only if the dialogue is finished and open.

Finished and closed: the proposer wins.

Finished and open: the opponent wins.

Definition of Validity: A thesis A is said to be dialogically valid (in classical or intuitionist logic) when all games of the dialogue $\mathrm{D}_{(\mathrm{A})}$ are closed. ${ }^{10}$

\section{Structural rules for the actualist phase of FDL}

This stage begins with the attack from $\mathrm{O}$ to $\mathrm{P}$ in respect of the dependencies of the constants used. For this purpose, it is stated that:

- To attack the dependency relationship, the proposer must win the first stage of the game (dialog symbolically terminated) according to:

Definition: We say that a dialog is symbolically finished if and only if the dialog is closed and finished according to the rules of the symbolic stage.

According to the above, we have the following rule:

(RD-0) X can only challenge the ontological dependency relation by application of (RD-1)(RD-5) once the symbolic phase has ended and on the last atomic formula played by $\mathrm{Y}$.

Definition: (i) We call "symbolic" the phase in which the symbolic status of the objects to which the constants played correspond has not yet been specified by the application

${ }^{10}$ It is possible to prove that the dialogical definition of validity coincides with the standard definition. The first formulations of the evidence were developed by Kuno Lorenz in his $\mathrm{PhD}$ thesis (repeated in Lorenzen and Lorenz, 1978). Felscher (1985) proved equivalence with first-order intuitionist logic (by demonstrating the correspondence between intuitionist dialogues and the intuitionist sequent calculus); while Stegmüller (1964) established equivalence in the case of classical first-order logic. Rahman (1993, pp. 88-107), who developed the idea that dialogues for validity could be seen as a theory of evidence structure for constructing tableau systems, directly proved the equivalence between the two types of dialogues and the corresponding semantic tableau, from which the result extends to the corresponding sequent calculus. 
of the rules (RD-1)-(RD-5); (ii) we call "actualist" the phase in which we apply the rules (RD-1)-(RD-5).

(RD-1) when $\mathrm{X}$ plays an atomic formula containing a $\mathrm{k}_{\mathrm{i}}, \mathrm{Y}$ can challenge $\mathrm{X}$ with the following question: "?- $D \mathrm{k}_{\mathrm{i}} \mathrm{k}_{\mathrm{j}}$, i.e., ask for the kind of ontological dependence on $\mathrm{k}_{\mathrm{i}}$ (dependent $\left[\mathrm{k}_{\mathrm{i}}=\mathrm{k}_{\mathrm{j}}\right]$ or independent $\left.\left[\mathrm{k}_{\mathrm{i}} \neq \mathrm{k}_{\mathrm{j}}\right]\right)$.

We have:

\begin{tabular}{ccc}
\hline Formulae & Challenge & Defence \\
\hline $\mathrm{X}-$ !- $A \mathrm{k}_{\mathrm{i}}$ & $\mathrm{Y}-$ ?-D $D \mathrm{k}_{\mathrm{i}}$ & $\mathrm{X}-$ !-D $\mathrm{k}_{\mathrm{i}} \mathrm{k}_{\mathrm{j}}$ \\
\hline
\end{tabular}

Two cases:

\begin{tabular}{|c|c|c|c|c|}
\hline \multicolumn{2}{|c|}{$\mathrm{O}$} & \multicolumn{2}{|c|}{$\mathrm{P}$} \\
\hline $\mathrm{n}$ & $\mathrm{Ak}_{1}$ & & & \\
\hline $\mathrm{n}+2$ & $D \mathrm{k}_{1} \mathrm{k}_{\mathrm{j}}$ & $\mathrm{n}$ & $?-D \mathrm{k}_{1} \mathrm{k}_{\mathrm{j}}$ & $\mathrm{n}+1$ \\
\hline
\end{tabular}

or

\begin{tabular}{|c|c|c|c|c|}
\hline \multicolumn{2}{|c|}{$\mathrm{O}$} & \multicolumn{2}{|c|}{} \\
\hline & & & $\mathrm{Ak}_{1}$ & $\mathrm{n}$ \\
\hline $\mathrm{n}+1$ & $?-D \mathrm{k}_{1} \mathrm{k}_{\mathrm{j}}$ & $\mathrm{n}$ & $D \mathrm{k}_{1} \mathrm{k}_{\mathrm{j}}$ & $\mathrm{n}+2$ \\
\hline
\end{tabular}

(RD-2) when $\mathrm{X}$ plays an atomic formula containing a ki and that the same ki has been used by $\mathrm{X}$ to defend an existential quantifier or to attack a universal quantifier (introduced), $\mathrm{Y}$ may ask him "? $-D k_{i} k_{1}$ " Y may demand that he justifies that ki is in a relation of reflexive dependence, i.e., that ki exists independently. $\mathrm{X}$ defends itself justifying the relation of reflexive dependence: $D \mathrm{k}_{\mathrm{i}} \mathrm{k}_{\mathrm{i}}$.

(RD-3) when $\mathrm{X}$ concedes an ontological dependence relation Dkikj with $\mathrm{k}_{\mathrm{i}} \neq \mathrm{k}_{\mathrm{i}}$, that is to say that $\mathrm{k}_{\mathrm{i}}$ is a non-existent that depends on $\mathrm{k}_{\mathrm{j}}$, it concedes at the same time $D \mathrm{k}_{\mathrm{j}} \mathrm{k}_{\mathrm{j}}$.

Corollary of the formal rule (RS-3): P does not have the right to introduce an ontological dependency relationship.

If the Proponent has won in the first part (symbolic phase) and there is a branching, the opponent has the right to question the status of the objects corresponding to the constants played at the end of each branching. For example: 


\begin{tabular}{|c|c|c|c|c|c|c|c|c|c|c|c|}
\hline \multicolumn{6}{|c|}{$\mathrm{O}$} & \multicolumn{6}{|c|}{$\mathbf{P}$} \\
\hline & & & & & & & $\left(\mathrm{Ak}_{1} \wedge{ }^{\prime}\right.$ & $x-$ & $\exists \mathrm{x}($ & $\mathrm{x} \wedge \exists \mathrm{xAx})$ & 0 \\
\hline 1 & \multicolumn{4}{|c|}{$\mathrm{Ak}_{1} \wedge \exists \mathrm{xAx}$} & 0 & & \multicolumn{4}{|c|}{$\exists x(A x \wedge \exists x A x)$} & 2 \\
\hline 3 & \multicolumn{4}{|c|}{$?-\$$} & 2 & & \multicolumn{4}{|c|}{$\mathrm{Ak}_{1} \wedge \exists \mathrm{xAx}$} & 4 \\
\hline 5 & $? \wedge_{1}$ & 4 & $5^{\prime}$ & $? \wedge_{2}$ & 4 & & $\mathrm{Ak}_{1}$ & 8 & & $\exists x A x$ & $8^{\prime}$ \\
\hline 7 & $\mathrm{Ak}_{1}$ & & $7^{\prime}$ & $\exists x A x$ & & 1 & $? \wedge_{1}$ & 6 & 1 & $? \wedge_{2}$ & 6 \\
\hline \multirow[t]{3}{*}{9} & $?-D \mathrm{k}_{2} \mathrm{k}_{\mathrm{j}}$ & 8 & $9^{\prime}$ & $?-\exists$ & $8^{\prime}$ & & & & & $\mathrm{Ak}_{2}$ (:) & $12^{\prime}$ \\
\hline & & & $11^{\prime}$ & $\mathrm{Ak}_{2}$ & & & & & $7^{\prime}$ & $?-\exists$ & $10^{\prime}$ \\
\hline & & & $13^{\prime}$ & $?-D \mathrm{k}_{2} \mathrm{k}_{2}$ & $12^{\prime}\left(8^{\prime}\right)$ & & & & & & \\
\hline
\end{tabular}

(RD-4) X can update a constant (repeat the defence of an existential quantifier or the challenge on a universal quantifier) if and only if $Y$ has introduced a new constant of which $X$ can be served or that $Y$ has granted this constant in a reflexive ontological dependency relationship $\left(D \mathrm{k}_{\mathrm{i}} \mathrm{k}_{\mathrm{i}}\right)$.

Definition: We say that $\mathrm{X}$ symbolically confers an atomic formula when in the symbolic phase it defends itself from a challenge ?-ki of $Y$ (on a universal quantifier) by affirming an atomic formula $\phi\left[\mathrm{x} / \mathrm{k}_{\mathrm{i}}\right]$.

(RD-5) when $\mathrm{X}$ has symbolically conceded an atomic formula $\phi\left[\mathrm{x} / \mathrm{k}_{\mathrm{i}}\right]$ which is then determined to be a dependent object in the actualist phase, then $\mathrm{X}$ can annul the concession of the atomic formula $\phi\left[\mathrm{x} / \mathrm{k}_{\mathrm{i}}\right]$, i.e. the concession had no value until the quantifiers were interpreted in an actualist manner.

We have then that a symbolic constant is one for which the ontological status of the corresponding entity continues to be indeterminate (as dependent or independent).

Definition: We will call "symbolic" a totally new constant played by P, a constant that appears in the initial thesis or introduced by the opponent, and that continues indeterminate according to the rules (RD-1)-(RD-5).

Let's see as examples the cases of Specification and Particularization:

\begin{tabular}{|c|c|c|c|c|c|}
\hline \multicolumn{2}{|c|}{ O } & \multicolumn{2}{c|}{ P } \\
\hline & & & & $\mathrm{Ak}_{1} \rightarrow \exists \mathrm{xAx}$ & 0 \\
\hline 1 & $\mathrm{Ak}_{1}$ & 0 & & $\exists \mathrm{xAx}$ & 2 \\
\hline 3 & $?-\exists$ & 2 & & $\mathrm{Ak}_{1}$ & 4 \\
\hline 5 & $?-D \mathrm{k}_{1} \mathrm{k}_{1}$ & $4(3)$ & & & \\
\hline 7 & $D \mathrm{k}_{1} \mathrm{k}_{2} \odot$ & & 1 & $?-D \mathrm{k}_{1} \mathrm{k}_{\mathrm{i}}$ & 6 \\
\hline
\end{tabular}




\begin{tabular}{|c|c|c|c|c|c|}
\hline \multicolumn{2}{|c|}{ O } & \multicolumn{3}{c|}{ P } \\
\hline & & & & $\forall x A x \rightarrow \mathrm{Ak}_{1}$ & 0 \\
\hline 1 & $\forall \mathrm{xAx}$ & 0 & & $\mathrm{Ak}_{1}$ & 4 \\
\hline 3 & {$\left[\mathrm{Ak}_{\mathrm{t}}\right]$} & & 1 & $? \mathrm{k}_{1}$ & 2 \\
\hline 5 & $?-D \mathrm{k}_{1} \mathrm{k}_{1}$ & $4(2)$ & & & \\
\hline 7 & $D \mathrm{k}_{1} \mathrm{k}_{2}$ & & 3 & $?-D \mathrm{k}_{1} \mathrm{k}_{\mathrm{i}}$ & 6 \\
\hline 9 & $\mathrm{Ak}_{2} \odot$ & & 1 & $? \mathrm{k}_{2}$ & 8 \\
\hline
\end{tabular}

For the case of Smullyan's formulae:

\begin{tabular}{|c|c|c|c|c|c|}
\hline \multicolumn{3}{|c|}{$\mathrm{O}$} & \multicolumn{3}{c|}{$\mathrm{P}$} \\
\hline & & & & $\exists \mathrm{x}(\mathrm{Ax} \rightarrow \forall \mathrm{xAx})$ & 0 \\
\hline 1 & $?-\exists$ & 0 & & $\mathrm{Ak}_{1} \rightarrow \forall \mathrm{xAx}$ & 2 \\
\hline 3 & $\mathrm{Ak}_{1}$ & 2 & & $\forall \mathrm{xAx}$ & 4 \\
\hline 5 & $? \mathrm{k}_{2}$ & 4 & & $\mathrm{Ak}_{2}$ & 8 \\
\hline & & & & $\mathrm{Ak}_{2} \rightarrow \forall \mathrm{xAx}$ & 6 \\
\hline 7 & $\mathrm{Ak}_{2}$ & 6 & & & \\
\hline 9 & $?-D \mathrm{k}_{2} \mathrm{k}_{2}$ & $8(1)$ & & $D \mathrm{k}_{2} \mathrm{k}_{2} \odot$ & 12 \\
\hline 11 & $D \mathrm{k}_{2} \mathrm{k}_{2}$ & & $5(7)$ & $?-D \mathrm{k}_{2} \mathrm{k}_{2}$ & 10 \\
\hline
\end{tabular}

For $\mathrm{Ak}_{1} \rightarrow \mathrm{Ak}_{1}$

\begin{tabular}{|c|c|c|c|c|c|}
\hline \multicolumn{2}{|c|}{$\mathrm{O}$} & \multicolumn{3}{c|}{ P } \\
\hline & & & & $\mathrm{Ak}_{1} \rightarrow \mathrm{Ak}_{1}$ & 0 \\
\hline 1 & $\mathrm{Ak}_{1}$ & 0 & & $\mathrm{Ak}_{1}$ & 2 \\
\hline 3 & $?-D \mathrm{k}_{1} \mathrm{k}_{\mathrm{j}}$ & 2 & & $D \mathrm{k}_{1} \mathrm{k}_{1} / D \mathrm{k}_{1} \mathrm{k}_{2}$ & \\
\hline 5 & $D \mathrm{k}_{1} \mathrm{k}_{1} / D \mathrm{k}_{1} \mathrm{k}_{2}$ & & 1 & $?-D \mathrm{k}_{1} \mathrm{k}_{\mathrm{j}}$ & 4 \\
\hline
\end{tabular}

$\mathrm{P}$ wins on the symbolic stage: the thesis has a winning strategy for indeterminate constants (symbolic). Later $\mathrm{P}$ wins the actualist stage, then the thesis has a winning strategy for existent and non-existent beings: in $5, \mathrm{O}$ can answer either of the two $\left(D \mathrm{k}_{1} \mathrm{k}_{1}\right.$ or $\left.D \mathrm{k}_{1} \mathrm{k}_{2}\right)$. 


\begin{tabular}{|c|c|c|c|c|c|}
\hline \multicolumn{3}{|c|}{ O } & \multicolumn{2}{c|}{ P } \\
\hline & & & & $\exists \mathrm{x}(\mathrm{Ax} \rightarrow \mathrm{Ax})$ & 0 \\
\hline 1 & $?-\exists$ & 0 & & $\mathrm{Ak}_{1} \rightarrow \mathrm{Ak}_{1}$ & 2 \\
\hline 3 & $\mathrm{Ak}_{1}$ & 2 & & $\mathrm{Ak}_{1}$ & 4 \\
\hline 5 & $?-D \mathrm{k}_{1} \mathrm{k}_{1}$ & $4(0)$ & & & \\
\hline 7 & $D \mathrm{k}_{1} \mathrm{k}_{2} \odot$ & & 3 & $?-D \mathrm{k}_{1} \mathrm{x}$ & 6 \\
\hline
\end{tabular}

In the latter case, specification, $\mathrm{P}$ does not have a winning strategy at the actualist stage.

Other existential formulas do have EG as is the case of Smullyan that we saw above.

The following case corresponds to an identity, P wins at the actualist stage.

\begin{tabular}{|c|c|c|c|c|c|}
\hline \multicolumn{3}{|c|}{ O } & \multicolumn{3}{c|}{$P$} \\
\hline & & & & $\exists x A x \rightarrow \exists x A x$ & 0 \\
\hline 1 & $\exists x A x$ & 0 & & $\exists x A x$ & 2 \\
\hline 3 & $?-\exists$ & 2 & & $\mathrm{Ak}_{1}$ & 6 \\
\hline 5 & $\mathrm{Ak}_{1}$ & & 1 & $?-\exists$ & 4 \\
\hline 7 & $?-D \mathrm{k}_{1} \mathrm{k}_{1}$ & $6(2)$ & & $D \mathrm{k}_{1} \mathrm{k}_{1} \odot$ & 10 \\
\hline 9 & $D \mathrm{k}_{1} \mathrm{k}_{1}$ & & $5(1)$ & $?-D \mathrm{k}_{1} \mathrm{k}_{1}$ & 8 \\
\hline
\end{tabular}

Finally

\begin{tabular}{|c|c|c|c|c|c|}
\hline \multicolumn{2}{|c|}{$\mathrm{O}$} & \multicolumn{2}{c|}{$\mathrm{P}$} \\
\hline & & & & $\mathrm{Ak}_{1} \rightarrow \forall \mathrm{x}\left(\mathrm{Ax} \rightarrow \mathrm{Ak}_{1}\right)$ & 0 \\
\hline 1 & $\mathrm{Ak}_{1}$ & 0 & & $\forall \mathrm{x}\left(\mathrm{Ax} \rightarrow \mathrm{Ak}_{1}\right)$ & 2 \\
\hline 3 & $? \mathrm{k}_{2}$ & 2 & & $\mathrm{Ak}_{2} \rightarrow \mathrm{Ak}_{1}$ & 4 \\
\hline 5 & $\mathrm{Ak}_{2}$ & 4 & $\mathrm{Ak}_{1}$ & 6 \\
\hline 7 & $?-D \mathrm{k}_{1} \mathrm{x}$ & 6 & & $D \mathrm{k}_{1} \mathrm{k}_{1} / D \mathrm{k}_{1} \mathrm{k}_{2}$ & 10 \\
\hline 9 & $D \mathrm{k}_{1} \mathrm{k}_{1} / D \mathrm{k}_{1} \mathrm{k}_{2}$ & & 1 & $?-D \mathrm{k}_{1} \mathrm{x}$ & 8 \\
\hline
\end{tabular}

\section{Some final remarks on targetless models and FDL}

The $\mathrm{k}_{\mathrm{i}}$ constants of the FDL object language correspond to parts of the model or to the model itself. For example, when we infer from $M$ that $k_{1}$ verifies $A k_{1} \rightarrow \forall x\left(A x \rightarrow A k_{1}\right)$, (A being a relevant property of $\mathrm{M}$ ), we are at the same time formulating a hypothesis about the phenomena to which the model points. In this sense, for targetless models (according to $i$, ii or iii), we believe that the $\mathrm{k}_{\mathrm{i}}$ mentioned corresponds to the constants of the 
first stage of FDL: the symbolic stage. Indeed, it is worth noting that there is a parallelism between the ontological status of the entities considered as symbolic by Hugh MacColl (1906) and the ontologically uncertain phenomena to which the model points.

Thus, FDL has two complementary stages: a first stage (symbolic) where the winning strategies correspond to hypotheses formulated and defended on the phenomena without ontological commitments. In other words, in this first stage, the status of the singular terms in the affirmations (thesis) with winning strategies is symbolic. The second stage, the actualist one, is a stage of discernment and determination. In effect, it is the information that allows us to discern between existent and non-existent beings (captured in FDL as dependent and non-dependent). The most relevant part of this information is that it allows us to detect deceptive inferential steps, that is, those that would lead us to formulate (erroneously) committed ontological hypotheses about ontologically uncertain phenomena, such as $\mathrm{Ak}_{1} \rightarrow \exists \mathrm{xAx}$ (Specification).

\section{Conclusions}

The aim of this article was to develop a Free Dialogic Logic (FDL) that offers necessary conditions to address the logical difficulties presented when modeling ontologically uncertain phenomena. We have focused especially on the case of classical logic because it is one of the most widespread and widely used logical frames in science. The difficulties that arise when modeling ontologically uncertain phenomena are mainly due to the restrictions and limitations imposed by the semantics of classical logic. We show in our article that without these considerations the inferential function fulfilled by the model through surrogate reasoning leads to erroneous statements about the ontological status of the phenomena to which the model points. Indeed, the most relevant part of the information that delivers FDL is that it allows us to detect deceptive inferential steps. For example, in the case of the generation of committed ontological hypotheses due to $\mathrm{Ak}_{1} \rightarrow \exists \mathrm{xAx}$ (Specification).

The structure of our FDL has two complementary phases: a first stage (symbolic) where the winning strategies correspond to hypotheses formulated and defended on a target system without ontological commitments. The second stage, the actualist one, is a stage of discernment that allows us to put down all the formulas that would commit us to the ontological status of the phenomena.

Finally, we would like to point out that a consequence of this view on the modeling of ontologically uncertain phenomena is that it should be considered separately from the target system (cf. Cassini, 2018). We believe that while the former is a part of the phenomena and could be absent as proposed by the model, the latter, the target system, can be considered as a hypothetical complement that is elaborated at the same time with the model. This separation would prevent the modeling process from being invalidated in the face of the uncertain ontological condition of what the model is targeting. As we pointed out above, the recognition of a problematic target in phenomena and the elaboration of the respective model is a crucial part of the modeling process and we believe it is worth developing in a future article. 


\section{Acknowledgments}

The author would like to thank Rodrigo Lopez Orellana (Universidad de Valparaíso) who contributed fruitfully to the discussion around the themes of this article. I would also like to thank Shahid Rahman (Université de Lille) for his wise comments and advice during fruitful exchanges with regard to the development of a free dialogical logic in the dialogical pragmatism' approach he leads. Many thanks to ANID (Chile) and the Instituto de Filosofía, Universidad de Valparaíso, for fostering the preparation of the present article. Finally let me express my indebtedness to the reviewer for crucial remarks and suggestions.

\section{Appendix: Standard Dialogical Logic ${ }^{11}$}

Let $L$ be a first-order language built as usual upon the propositional connectives, the quantifiers, a denumerable set of individual variables, a denumerable set of individual constants and a denumerable set of predicate symbols (each with a fixed arity).

We extend the language $L$ with two labels $\mathbf{O}$ and $\mathbf{P}$, standing for the players of the game, and the question mark '?'. When the identity of the player does not matter, we use variables $\mathbf{X}$ or $\mathbf{Y}$ (with $\mathbf{X} \neq \mathbf{Y}$ ). A move is an expression of the form ' $\mathrm{X}-e$ ', where $e$ is either a formula $\varphi$ of $L$ or the form '? $\left[\varphi_{1}, \ldots, \varphi_{n}\right]$ '.

We now present the rules of dialogical games. There are two distinct kinds of rules named particle (or local) rules and structural rules. We start with the particle rules.

\begin{tabular}{|c|c|c|c|c|}
\hline Previous move & $\mathrm{X}-\varphi \wedge \psi$ & $X-\varphi \vee \psi$ & $X-\varphi \rightarrow \psi$ & $\mathrm{X}-\neg \varphi$ \\
\hline Challenge & $\begin{array}{c}\mathrm{Y}-?[\varphi] \text { or } \\
\mathrm{Y}-?[\psi]\end{array}$ & $\mathrm{Y}-?[\varphi, \psi]$ & $Y-\varphi$ & $Y-\varphi$ \\
\hline Defence & $\begin{array}{c}\mathrm{X}-\boldsymbol{\varphi} \\
\text { resp. } \mathrm{X}-\psi\end{array}$ & $\begin{array}{c}X-\varphi \\
\text { or } X-\psi\end{array}$ & $X-\psi$ & - \\
\hline
\end{tabular}

11 The following brief presentation of standard dialogical logic is due to Nicolas Clerbout. The main original articles on dialogical logic are collected in Lorenzen and Lorenz (1978). For an historical overview see Lorenz (2001). Other articles have been collected more recently in Lorenz (2008, 2010a, 2010b). A detailed account of recent developments since, say, Rahman (1993) and Felscher (1994), can be found in Rahman and Keiff (2005) and Keiff (2011). For the underlying metalogic see Clerbout (2013a, 2013b). For a textbook presentation: Rückert (2011). For the key role of dialogic in regaining the link between dialectics and logic, see Rahman and Keiff (2010). Fiutek et al. (2010) study the dialogical approach to belief revision. Clerbout et al. (2011) studied Jain Logic in the dialogical framework. Popek (2012, pp. 223-244) develops a dialogical reconstruction of medieval obligationes. See also Magnier (2013) — on dynamic epistemic logic and legal reasoning in a dialogical framework. Rahman et al. (2018) studied Immanent reasoning or equality in action. 


\begin{tabular}{lcc}
\hline Previous move & $\mathrm{X}-\forall \mathrm{x} \varphi$ & $\mathrm{X}-\exists \mathrm{x} \varphi$ \\
\hline Challenge & $\mathrm{Y}-?[\varphi(\mathrm{a} / \mathrm{x})]$ & $\mathrm{Y}-?\left[\varphi\left(\mathrm{a}_{1} / \mathrm{x}\right), \ldots, \varphi\left(\mathrm{a}_{\mathrm{n}} / \mathrm{x}\right)\right]$ \\
\hline Defence & $\mathrm{X}-\varphi(\mathrm{a} / \mathrm{x})$ & $\begin{array}{c}\mathrm{X}-\varphi\left(\mathrm{a}_{\mathrm{i}} / \mathrm{x}\right) \\
\text { with } 1 \leq \mathrm{i} \leq \mathrm{n}\end{array}$ \\
\hline
\end{tabular}

In this table, the $a_{i}$ are individual constants and $\varphi\left(a_{i} / x\right)$ denotes the formula obtained by replacing every occurrence of $x$ in $\varphi$ by $a_{i}$. When a move consists in a question of the form '? $\left[\varphi_{1}, \ldots, \varphi_{n}\right]$ ', the other player chooses one formula among $\varphi_{1}, \ldots, \varphi_{n}$ and plays it. We can thus distinguish between conjunction and disjunction on the one hand, and universal and existential quantification on the other hand, in terms of which player has a choice. In the cases of conjunction and universal quantification, the challenger chooses which formula he asks for. Conversely, in the cases of disjunction and existential quantification, the defender is the one who can choose between various formulas. Notice that there is no defence in the particle rule for negation.

Particle rules provide an abstract description of how the game can proceed locally: they specify the way a formula can be challenged and defended according to its main logical constant. In this way we say that these rules govern the local level of meaning. Strictly speaking, the expressions occurring in the table above are not actual moves because they feature formulas schemata and the players are not specified. Moreover, these rules are indifferent to any particular situations that might occur during the game. For these reasons we say that the description provided by the particle rules is abstract. The words "challenge" and "defence" are convenient to name certain moves according to their relationship with other moves. Such relationships can be precisely defined in the following way. Let $S$ be a sequence of moves. The function $p_{\Sigma}$ assigns a position to each move in $\sum$, starting with 0 . The function $F_{\Sigma}$ assigns a pair $[m, Z]$ to certain moves $N$ in $\sum$, where $m$ denotes a position smaller than $p_{\Sigma}(N)$ and $Z$ is either $C$ or $D$, standing respectively for "challenge" and "defence". That is, the function $F_{\Sigma}$ keeps track of the relations of challenge and defence as they are given by the particle rules. A play (or dialogue) is a legal sequence of moves, i.e., a sequence of moves which observes the game rules. The rules of the second kind that we mentioned, the structural rules, give the precise conditions under which a given sentence is a play. The dialogical game for $\varphi$, written $\mathrm{D}(\varphi)$, is the set of all plays with $\varphi$ as the thesis (see the Starting rule below). The structural rules are the following:

SR0 (Starting rule) Let $\varphi$ be a complex formula of $L$. For every $\pi \in D(\varphi)$ we have:

$$
\begin{aligned}
& -p_{\pi}(\mathbf{P}-\varphi)=0, \\
& -p_{\pi}(\mathbf{O}-\mathrm{n}:=i)=1, \\
& -p_{\pi}(\mathbf{P}-\mathrm{m}:=j)=2
\end{aligned}
$$

In other words, any play $\pi$ in $D(\varphi)$ starts with $\mathbf{P}-\varphi$. We call $\varphi$ the thesis of the play and of the dialogical game. After that, the Opponent and the Proponent successively choose a positive integer called repetition rank. The role of these integers is to ensure that every play ends after finitely many moves, in a way specified by the next structural rule. 


\section{SR1 (ClassicAl GAME-PLAYING RULE)}

- Let $\pi \in \mathrm{D}(\varphi)$. For every $M$ in $\pi$ with $p_{\pi}(M)>2$ we have $F_{\pi}(M)=\left[m^{\prime}, Z\right]$ with $m^{\prime}<p_{\pi}(M)$ and $Z \in\{C, D\}$

- Let $r$ be the repetition rank of player $X$ and $\pi \in D(\varphi)$ such that

- the last member of $\pi$ is a Y move,

- $M_{0}$ is a Y move of position $m_{0}$ in $\pi$,

- $M_{1}, \ldots, M_{\mathrm{n}}$ are $\mathrm{X}$ moves in $\pi$ such that $F_{\pi}\left(M_{1}\right)=\ldots=F_{\pi}\left(M_{\mathrm{n}}\right)=\left[m_{0}, Z\right]$.

Consider the sequence ${ }^{12} \pi^{\prime}=\pi^{*} N$ where $N$ is an $\mathbf{X}$ move such that $F_{\pi^{\prime}}(N)=\left[m_{0}, Z\right]$. We have $\pi^{\prime} \in \mathrm{D}(\varphi)$ only if $\mathrm{n}<r$.

The first part of the rule states that every move after the choice of repetition ranks is either a challenge or a defence. The second part ensures finiteness of plays by setting the player's repetition rank as the maximum number of times he can challenge or defend against a given move of the other player.

SR2 (Formal rule) Let y be an elementary sentence, $N$ be the move $\mathbf{P}-\psi$ and $M$ be the move $\mathrm{O}-\psi$. A sequence $\mathrm{p}$ of moves is a play only if we have: if $N \in \pi$ then $M \in \pi$ and $p_{\pi}(M)<p_{\pi}(N)$.

A play is called terminal when it cannot be extended by further moves in compliance with the rules. We say it is $\mathbf{X}$ terminal when the last move in the play is an $\mathbf{X}$ move.

\section{SR3 (Winning rule) Player $\mathrm{X}$ wins the play p only if it is $\mathrm{X}$ terminal.}

Consider for example the following sequences of moves: P-Qa $\rightarrow \mathrm{Qa}, \mathrm{O}-\mathrm{n}:=1, \mathbf{P}-\mathrm{m}:=12$, O-Qa, P-Qa.

We often use a convenient table notation for plays. For example, we can write this play as follows:

\begin{tabular}{|c|c|c|c|c|c|}
\hline & O & & & P & \\
\hline & & & & $\mathrm{Qa} \rightarrow \mathrm{Qa}$ & 0 \\
\hline 1 & $\mathrm{n}:=1$ & & & $\mathrm{~m}:=12$ & 2 \\
\hline 3 & $\mathrm{Qa}$ & $(0)$ & & $\mathrm{Qa}$ & 4 \\
\hline
\end{tabular}

The numbers in the external columns are the positions of the moves in the play. When a move is a challenge, the position of the challenged move is indicated in the internal columns, as with move 3 in this example. Notice that such tables carry the information given by the functions $p$ and $F$ in addition to represent the play itself.

However, when we want to consider several plays together - or example when building a strategy - such tables are not that perspicuous. So we do not use them to deal with dialogical games for which we prefer another perspective. The extensive form of the dialogical game $D(\varphi)$ is simply the tree representation of it, also often called the game-tree. More precisely, the extensive form $\mathrm{E}_{\varphi}$ of $\mathrm{D}(\varphi)$ is the tree $(T, I, S)$ such that:

${ }_{12}$ We use $\pi^{*} N$ to denote the sequence obtained by adding move $N$ to the play $\pi$. 

i) Every node $t$ in $T$ is labelled with a move occurring in $\mathrm{D}(\varphi)$
ii) $l: T \rightarrow \mathrm{N}$
iii) $S \subseteq T^{2}$ with:

- There is a unique $t_{0}$ (the root) in $T$ such that $I\left(t_{0}\right)=0$, and $t_{0}$ is labelled with the thesis of the game.

- For every $t \neq t_{0}$ there is a unique $t^{\prime}$ such that $t^{\prime} S t$.

- For every $t$ and $t^{\prime}$ in $T$, if $t S t^{\prime}$ then $I\left(t^{\prime}\right)=I(t)+1$.

- Given a play $\mathrm{p}$ in $\mathrm{D}(\varphi)$ such that $p_{\pi}\left(M^{\prime}\right)=p_{\pi}(M)+1$ and $t, t^{\prime}$ respectively labelled with $M$ and $M^{\prime}$, then $t S t^{\prime}$.

A strategy for Player $\mathrm{X}$ in $\mathrm{D}(\varphi)$ is a function which assigns an $\mathrm{X}$ move $M$ to every non terminal play $\pi$ with a $\mathrm{Y}$ move as last member such that extending $\pi$ with $M$ results in a play. An $\mathbf{X}$ strategy is winning if playing according to it leads to $\mathbf{X}^{\prime}$ 's victory no matter how $\mathbf{Y}$ plays.

A strategy can be considered from the viewpoint of extensive forms: the extensive form of an $\mathrm{X}$ strategy $s$ in $\mathrm{D}(\varphi)$ is the tree-fragment $\mathrm{E}_{\varphi, \sigma}=\left(T_{\sigma}, I_{\sigma}, S_{\sigma}\right)$ of $\mathrm{E}_{\varphi}$ such that:

i) The root of $E_{\varphi, \sigma}$ is the root of $E_{\varphi}$.

ii) Given a node $t$ in $\mathrm{E}_{\varphi}$ labelled with an $\mathrm{X}$ move, we have that $t S_{\sigma} t^{\prime}$ whenever $t S t$ '.

iii) Given a node $t$ in $\mathrm{E}_{\varphi}^{\varphi}$ labelled with a $\mathrm{Y}$ move and with at least one $t^{\prime}$ such that $t S t^{\prime}$, then there is a unique $s(t)$ in $T_{\sigma}$ where $t S_{\sigma} s(t)$ and $s(t)$ is labelled with the $\mathrm{X}$ move prescribed by s.

Here are some examples of results which pertain to the level of strategies ${ }^{13}$.

1. Winning $\mathbf{P}$ strategies and leaves. Let $\mathrm{w}$ be a winning $\boldsymbol{P}$ strategy in $\mathrm{D}(\varphi)$. Then every leaf in $\mathrm{E}_{\varphi, \mathrm{w}}$ is labelled with a P signed atomic sentence.

2. Determinacy. There is a winning $X$ strategy in $\mathrm{D}(\varphi)$ if and only if there is no winning $Y$ strategy in $\mathrm{D}(\varphi)$.

3. Soundness and Completeness of Tableaux. Consider first-order tableaux and first-order dialogical games. There is a tableau proof for $\varphi$ if and only if there is a winning $\boldsymbol{P}$ strategy in $\mathrm{D}(\varphi)$.

By soundness and completeness of the tableau method with respect to model-theoretical semantics, it follows that existence of a winning $\mathbf{P}$ strategy coincides with validity: There is a winning $\boldsymbol{P}$ strategy in $\mathrm{D}(\varphi)$ if and only if $\varphi$ is valid.

\section{REFERENCES}

Bencivenga, E. (1986). Free logics. In D. Gabbay \& F. Guenthner (Eds.). Handbook of philosophical logic, vol. III: Alternatives to classical logic (pp. 373-426). Dordrecht: D. Reidel.

Cassini, A. (2018). Models without a target. ArtefaCToS, 7(2), 185-209.

Clerbout, N. (2013a). Etude sur quelques sémantiques dialogiques. Concepts fondamentaux et éléments de metathéorie. PHD thesis, Lille/Leiden: Universities of Lille 3 and Leiden, 2013.

13 These results are proven, together with others, in Clerbout (2013b). 
Clerbout, N. (2013b). First-order dialogical games and tableaux. Journal of Philosophical Logic, 43, 785-801. doi: $10.1007 / \mathrm{s} 10992-013-9289-\mathrm{z}$

Clerbout, N., Gorisse, M-H., \& Rahman, S. (2011). Context-sensitivity in jain philosophy. A dialogical study of Siddharsigani's commentary on the handbook of logic. Journal of Philosophical Logic, 40(5), 633-662.

Contessa, G. (2007). Scientific representation, interpretation, and surrogative reasoning. Philosophy of Science, 74(1), 48-68. doi: 10.1086/519478

Felscher, W. (1985). Dialogues as a foundation for intuitionistic logic. In D. Gabbay \& F. Guenthner (Eds.). Handbook of philosophical logic, vol. 3 (pp. 341-372). Dordrecht: Kluwer.

Felscher, W. (1994). Review of Jean E. Rubin's mathematical logic: applications and theory. The Journal of Symbolic Logic, 59, 670-671.

Fiutek, V., Rückert, H., \& Rahman, S. (2010). A dialogical semantics for Bonanno's system of belief revision. In P. Bour et al. (Eds.). Constructions (pp. 315-334). London: College Publications.

Frigg, R. \& Nguyen, J. (2017). Models and representation. In L. Magnani \& T. Bertolotti (Eds.). Handbook of model-based science (pp. 49-102). Dordrecht-New York: Springer.

Keiff, L. (2011). Dialogical logic. The Stanford Encyclopedia of Philosophy, Edward N. Zalta (ed.). Retrieved from https://plato.stanford.edu/archives/sum2011/entries/logic-dialogical/.

Lambert, K. (2003). Free logic: selected essays. Cambridge: Cambridge University Press.

Levenson, T. (2015). The hunt for Vulcan ... and how Einstein destroyed a planet, discovered relativity, and deciphered the universe. New York: Random House.

Levy, A. (2015). Modeling without models. Philosophical Studies 172(3), 781-798.

Lorenz, K. (2001). Basic objectives of dialogical logic in historical perspective. Synthese 127, 255-263.

Lorenz, K. (2008). Dialogischer Konstruktivismus. Berlin/New York: de Gruyter, 2008.

Lorenz, K. (2010a). Philosophische Variationen: Gesammelte Aufsätze unter Einschluss Gemeinsam mit Jürgen Mittelstrass geschriebener Arbeiten zu Platon und Leibniz. Berlin/New York: De Gruyter.

Lorenz, K. (2010b). Logic, language and method - On polarities in human experience. Berlin/New York: de Gruyter, 2010.

Lorenzen P. \& Lorenz, K. (1978). Dialogische Logik. Darmstadt: Wissenschaftliche Buchgesellschaft.

Luczak, J. (2017). Talk about toy models. Studies in History and Philosophy of Science Part B: Studies in history and philosophy of modern physics, 57, 1-7. doi: 10.1016/j.shpsb.2016.11.002

MacColl, H. (1906). Symbolic logic and its applications. Longmans, Green, London.

Magnier, S. (2013). Approche dialogique de la dynamique épistémique et de la condition juridique. London: College Publications.

Marion, M. \& Rückert, H. (2015). Aristotle on universal quantification: A study form the perspective of game semantics. History and Philosophy of Logic, 37(3), 201-229.

Popek, A. (2012). Logical dialogues from middle ages. In C. Barés et al. (Eds.). Logic of knowledge. Theory and applications (pp. 223-244). London: College Publications.

Rahman, S. (1993). Über Dialogue, protologische Kategorien und andere Seltenheiten. Frankfurt / Paris / New York: P. Lang.

Rahman, S. \& Keiff, L. (2005). On how to be a dialogician. In D. Vanderveken (Ed.). Logic, thought and action (pp. 359-408). Dordrecht: Kluwer.

Rahman, S. \& Keiff, L. (2010). La dialectique entre logique et rhétorique. Revue de Métaphysique et de Morale, 66(2), 149-178.

Rahman, S., Clerbout, N., \& Keiff, L. (2009). On dialogues and natural deduction. In G. Primiero \& S. Rahman (Eds.). Acts of knowledge: history, philosophy and logic. Essays dedicated to Göran Sundholm (pp. 301336). London: College Publications.

Rahman, S., Fishmann, M., \& Rückert, H. (1997). On dialogues and ontology. The dialogical approach to free logic. Logique et Analyse, 40(160), 357-374.

Rahman, S., McConaughey, Z., Klev, A., \& Clerbout, N. (2018). Immanent reasoning or equality in action. A plaidoyer for the play level. Series Logic, Argumentation \& Reasoning 18. Cham: Springer. 
Redmond, J. (2021). Representation and surrogate reasoning: A Proposal from Dialogical Pragmatism. In A. Cassini, \& J. Redmond (Eds.). Models and idealizations in science. Artifactual and fictional approaches. Cham: Springer. doi: 10.1007/978-3-030-65802-1. (Forthcomming).

Reicher, M. (2019). Nonexistent objects. The Stanford Encyclopedia of Philosophy, Edward N. Zalta (ed.). Retrieved from https://plato.stanford.edu/archives/win2019/entries/nonexistent-objects/

Rückert, H. (2011). Dialogues as a dynamic framework for logic. London: College Publications.

Shapiro, S. \& Kouri Kissel, T. (2018). Classical logic. The Stanford Encyclopedia of Philosophy, Edward N. Zalta (ed.). Retrieved from https://plato.stanford.edu/archives/spr2018/entries/logic-classical/

Suárez, M. (2015). Deflationary representation, inference, and practice. Studies in History and Philosophy of Science, 49, 36-47.

Swoyer, C. (1991). Structural representation and surrogative reasoning. Synthese, 87(3), 449-508. doi:10.1007/BF00499820

Thomasson, A. (1999). Fiction and metaphysics. Cambridge: Cambridge University Press.

JUAN REDMOND is a professor in the Institute of Philosophy at the Universidad de Valparaíso (Chile). His research interests include dialogical logic, philosophy of logic and epistemology. He published the books Logique dynamique de la fiction: pour une approche dialogique and How to play dialogues. An introduction to Dialogical Logic (co-author Matthieu Fontaine) both in College Publications, London, as well as some articles published in international peer-reviewed journals. He also runs the Journal of Humanities of Valparaíso (Scopus) and is Manager Editor of the Series Logic, Argumentation and Reasoning at Springer.

ADDRESS: Instituto de Filosofía, Facultad de Humanidades y Educación, Universidad de Valparaíso. Serrano 546, Barrio Puerto, Valparaíso, Chile. Email: juan.redmond@uv.cl

ORCID: https://orcid.org/0000-0003-3436-9490 